\title{
Iron solubility compared with in vitro digestion-Caco-2 cell culture method for the assessment of iron bioavailability in a processed and unprocessed complementary food for Tanzanian infants (6-12 months)
}

\author{
Ilse Pynaert ${ }^{1} *$, Charlotte Armah $^{2}$, Susan Fairweather-Tait ${ }^{2}$, Patrick Kolsteren ${ }^{3,4}$, John van Camp ${ }^{3}$ and \\ Stefaan De Henauw ${ }^{1,5}$ \\ ${ }^{1}$ Department of Public Health, Faculty of Medicine and Health Sciences, Ghent University, B-9000 Ghent, Belgium \\ ${ }^{2}$ Institute of Food Research, Norwich Research Park, Colney, Norwich NR4 7UA, UK \\ ${ }^{3}$ Department of Food Safety and Food Quality, Faculty of Agriculture and Applied Biological Sciences, Ghent University, \\ B-9000 Ghent, Belgium \\ ${ }^{4}$ Nutrition and Child Health Unit, Institute of Tropical Medicine, B-2000, Antwerp, Belgium \\ ${ }^{5}$ Department of Health Care, Vesalius, Hogeschool Gent, Belgium
}

(Received 5 May 2005 - Revised 8 December 2005 - Accepted 8 December 2005)

\begin{abstract}
The Fe solubility test is a commonly used, easy and relatively cheap in vitro tool for predicting Fe bioavailability in food matrices. However, the outcome of a recent field trial comparing the effect on Fe status of Tanzanian infants of processed $v$. unprocessed complementary foods (CF), with otherwise the same composition, challenged the validity of this test for predicting Fe bioavailability. In the solubility test, significant more soluble $\mathrm{Fe}$ was observed in processed compared with unprocessed foods (mean 18.8 (SEM 0.21) v. 4.8 (SEM 0.23) \%; P<0.001). However, in the field trial, no significant difference in Fe status was seen between processed and unprocessed CF groups after 6 months' follow-up. Therefore, twenty-four samples of these CF (twelve processed and twelve unprocessed batches) were analysed in triplicate for Fe availability using an in vitro digestionCaco-2 cell culture method and results were compared with solubility results. Significantly more soluble Fe was presented to Caco-2 cells in the processed compared with unprocessed samples (mean 11.5 (SEM 1.16) v. 8.5 (SEM 2.54) \%; $P=0.028$ ), but proportionally less Fe was taken up by the cells (mean 3.0 (SEM 0.40) v. 11.7 (SEM 2.22) \%; $P=0.007$ ). As a net result, absolute Fe uptake was lower (not significantly) in processed compared with unprocessed CF (mean 1.3 (SEM 0.16) v. 3.4 (SEM 0.83 ) nmol $/ \mathrm{mg}$ cell protein; $P=0.052$ ). These data clearly demonstrate that the Fe solubility test was not a good indicator of Fe bioavailability in these particular food matrices. In contrast, the results of an in vitro Caco-2 model supported the effects observed in vivo.
\end{abstract}

Iron: Bioavailability: Solubility: Caco-2 cells: Complementary food

Infants in developing countries still suffer on a large scale from stunted growth and Fe deficiency (World Health Organization, 2001; United Nations International Children's Emergency Fund, 2003). Children born with normal birth weight will generally satisfy their Fe needs during the first 6 months mainly through recycling of fetal $\mathrm{Hb}$. The $\mathrm{Fe}$ in breast milk is highly bioavailable, but represents only a limited fraction of their $\mathrm{Fe}$ supply. During and after the weaning period, the infant becomes increasingly dependent on complementary food $(\mathrm{CF})$ to meet physiological requirements for macro- and micronutrients (Michaelsen \& Friis, 1998; Kramer \& Kakuma, 2002). In developing countries, it has been observed that CF are largely cereal based with little variety. As a result, these foods are often low in energy density and nutrient content and contain significant quantities of micronutrient inhibitors, such as phytate and polyphenols. The consequence of a poor diet is that by the age of 12 months many children have stunted growth, are underweight and become increasingly Fe deficient (United Nations Standing Committee on Nutrition, 2004).

Traditional processing techniques have been used to improve energy density and Fe bioavailability of $\mathrm{CF}$ for young children in developing countries (Michaelsen \& Friis, 1998; Mensah \& Tomkins, 2003). Germination and fermentation are known to initiate starch hydrolysis and reduce levels of anti-nutritional factors such as phytate and tannins in cereal grains and legumes (Michaelsen \& Friis, 1998). These techniques are usually combined with heat treatments to guarantee microbial safety of the porridges (Michaelsen \& Friis, 1998; Kimanya et al. 2003). In a previous study, a CF was developed from local African ingredients that increased energy density and reduced the level of anti-nutritional factors. The aim was to improve growth and Fe status in infants (MbithiMwikya et al. 2002). The product was evaluated in Tanzania in a double-blind, randomised, placebo-controlled trial of 
infants aged 6-12 months (Mamiro et al. 2004). The results of the trial did not show a significant difference in growth or in Fe status parameters between the processed and unprocessed $\mathrm{CF}$ groups after a 6-month follow-up. A first explanation for this apparently paradoxical observation put forward was that the CF feeding frequency was about twice as high in the control group, thus compensating to some extent for the lower energy (and $\mathrm{Fe}$ ) density in the unprocessed $\mathrm{CF}$ after preparation of the porridges (Mamiro et al. 2004). However, even with this compensation, a difference in Fe parameters was expected.

The second explanation proposed was that the measured solubility (in vitro) did not estimate the more complex bioavailability (in vivo). The solubility method involves a simulation of the gastrointestinal digestion followed by a measurement of soluble $\mathrm{Fe}$ in the digest and thus covers only the first phase of the overall $\mathrm{Fe}$ absorption process. However, Caco- 2 cell models offer a more physiological tool for screening Fe availability in food matrices, particularly when combined with a simulated digestion step (Fairweather-Tait et al. 2006).

The aim of the present study was to compare Fe availability determined by the in vitro digestion-Caco- 2 cell culture method with Fe solubility for the processed and unprocessed $\mathrm{CF}$ and to examine these results in the context of an intervention study performed with the same foods in Tanzania.

\section{Materials and methods}

\section{Food samples}

$\mathrm{CF}$ samples were taken from twelve processed and twelve unprocessed production batches. The production process for both the processed and unprocessed $\mathrm{CF}$ was carried out under strictly standardised conditions. A detailed description of the CF is given by Mamiro et al. (2004). In summary, the processed CF consisted of germinated, autoclaved and dried finger millet $(65.2 \%)$ and kidney beans $(19.1 \%)$, roasted peanuts $(8 \%)$ and mango puree $(7.7 \%)$. The same ingredients in identical proportions were used for the unprocessed CF. The processed $\mathrm{CF}$ had a higher energy density (5.4 v. $1.6 \mathrm{~kJ} / \mathrm{g}$ porridge) and a lower concentration of phytates $(0.22 \quad v .1 .15 \% \mathrm{DM})$. The total $\mathrm{Fe}$ content was $4.74 \mathrm{mg} / 100 \mathrm{~g} \mathrm{DM}$ for the processed samples and $5.67 \mathrm{mg} /$ $100 \mathrm{~g} \mathrm{DM}$ for the unprocessed samples. The phytate:Fe molar ratios were 4.0:1 and 17.5:1 respectively for the processed and unprocessed samples.

\section{Solubility method}

The Fe solubility was determined using the pepsin-pancreatin method described by Miller et al. (1981) but without dialysis. The method involves simulating peptic digestion at $\mathrm{pH} 2$ by adding pepsin and $\mathrm{HCl}$ to the food samples, followed by an incubation period of $2 \mathrm{~h}$ at $37^{\circ} \mathrm{C}$. After incubation, the intestinal digestion is simulated by adjusting the $\mathrm{pH}$ to 7 using $\mathrm{NaHCO}_{3}$ and then adding pancreatin and bile salt, followed by another incubation period of $4 \mathrm{~h}$ at $37^{\circ} \mathrm{C}$. Finally, the samples were centrifuged and soluble $\mathrm{Fe}$ was measured in the supernatant fraction by atomic absorption spectrophotometry (Association of Official Analytical Chemists, 1995). The results are presented as percentage soluble $\mathrm{Fe}$, which is calculated as follows:

$$
\begin{aligned}
\text { Soluble Fe }(\%)= & (\text { soluble Fe }(\mathrm{mg} / 100 \mathrm{~g} \mathrm{DM}) / \\
& \text { total Fe }(\mathrm{mg} / 100 \mathrm{~g} \mathrm{DM})) \times 100 .
\end{aligned}
$$

\section{Cell culture}

Caco-2 cells were obtained from the European Collection of Cell Cultures (Salisbury, Wiltshire, UK) at passage 40 and used in experiments at passage 46 or 47 . Cells were seeded on collagen-treated six-well plates (Becton Dickinson Labware, Bedford, UK) at a density of 10000 cells $/ \mathrm{cm}^{3}$ in collagen-treated wells. The cells were grown in Dulbecco's Modified Eagle Medium (Sigma Aldrich, Irvine, UK) with $10 \%(\mathrm{v} / \mathrm{v})$ fetal bovine serum, $2 \%(\mathrm{v} / \mathrm{v})$ penicillin-streptomycin-glutamine solution and $1 \%(\mathrm{v} / \mathrm{v})$ non-essential amino acid solution. The cells were maintained at $37^{\circ} \mathrm{C}$ in an incubator with a $5 \% \mathrm{CO}_{2}-95 \%$ air atmosphere at constant humidity. The growth medium was changed every $2 \mathrm{~d}$. The cells were used in experiments $14 \mathrm{~d}$ post-seeding.

\section{In vitro digestion and iron uptake experiment}

The method used was based on Glahn et al. (1996). Approximately $3 \mathrm{~g}$ dried food sample, to which $8 \mathrm{ml} \mathrm{NaCl}(120 \mathrm{mmol} / \mathrm{l})$ was added, was homogenised. The $\mathrm{pH}$ of the resultant solution was adjusted to 2 using $\mathrm{HCl}(5 \mathrm{~mol} / \mathrm{l})$. A volume of $500 \mu \mathrm{l}$ $(128.4 \mathrm{kBq})$ of ${ }^{55} \mathrm{FeCl}_{3}-\mathrm{HCl}$ solution was than added to the food homogenate and the volume was made up to $10 \mathrm{ml}$ using $\mathrm{NaCl}(120 \mathrm{mmol} / \mathrm{l})$. The peptic digestion was carried out by adding $500 \mu \mathrm{l}$ pepsin solution $(0.4 \mathrm{~g}$ pepsin in $10 \mathrm{ml}$ $\mathrm{HCl}(0 \cdot 1 \mathrm{~mol} / \mathrm{l})$ and incubating for $60 \mathrm{~min}$ at $37^{\circ} \mathrm{C}$ on a rocking shaker (180 oscillations per min). Before the intestinal digestion, the existing growth medium surrounding the cells was removed and the cells were washed twice with $2 \mathrm{ml} 37^{\circ} \mathrm{C}$ Hank's balanced salt solution at $\mathrm{pH}$ 7. Then, $1.5 \mathrm{ml}$ Hank's balanced salt solution was used to cover the cells during the experiment. A two-chamber system was created by a sterilised insert with dialysis membrane, which was placed above the cells. After the peptic digestion period, the $\mathrm{pH}$ of the food samples was adjusted to 6 using $\mathrm{NaHCO}_{3}(1 \mathrm{~mol} / \mathrm{l})$. A pancreatin-bile solution $(0.1 \mathrm{~g}$ pancreatin and $0.6 \mathrm{~g}$ bile extract in $\left.50 \mathrm{ml} \mathrm{NaHCO}_{3}(0 \cdot 1 \mathrm{~mol} / \mathrm{l})\right)$ was then added and the $\mathrm{pH}$ adjusted to 7 using $\mathrm{NaOH}(0.5 \mathrm{~mol} / \mathrm{l})$. The volume was raised to $15 \mathrm{ml}$ with $\mathrm{NaCl}(120 \mathrm{mmol} / \mathrm{l})$ and the food samples were centrifuged ( $2 \mathrm{~min}$ at $800 \mathrm{rpm}$ ). A volume of $1.5 \mathrm{ml}$ of the supernatant fraction was pipetted into the upper chamber of the two-chamber system. After an incubation period of $2 \mathrm{~h}$ on a rocking shaker (130 oscillations per min), $500 \mu l$ of the content of the upper chamber was placed in a scintillation vial for determination of ${ }^{55} \mathrm{Fe}$. The insert was then removed and $500 \mu \mathrm{l}$ of the content of the lower chamber was placed in a second scintillation vial. The remaining Hank's balanced salt solution above the cells was then removed and the cells were washed twice with $2 \mathrm{ml}$ of a solution containing $\mathrm{NaCl}(140 \mathrm{mmol} / \mathrm{l}), \mathrm{KCl}(5 \mathrm{mmol} / \mathrm{l})$ and piperazine- $\mathrm{N}, \mathrm{N}^{\prime}$-bis (2-ethanesulfonic acid) $(10 \mathrm{mmol} / \mathrm{l})$ at $\mathrm{pH} 7$. Fe that was bound to the surface of the Caco- 2 cells was removed by the same solution as mentioned earlier, but to which sodium hydrosulfite $(5 \mathrm{mmol} / \mathrm{l})$ and bathophenanthrolene 
disulfonic acid $(1 \mathrm{mmol} / \mathrm{l})$ was added. After removing the surface-bound $\mathrm{Fe}$, the cells were washed a last time and $1 \mathrm{ml}$ $\mathrm{NaOH}(0.5 \mathrm{~mol} / \mathrm{l})$ was added to solubilise the cell monolayer. A $500 \mu \mathrm{l}$ sample was then transferred to a third scintillation vial. Finally, a second $500 \mu \mathrm{l}$ sample was transferred to a cryovial for protein analysis.

The experiment was performed four times to analyse all the twenty-four food samples in triplicate. Each time, a control in which no food sample was included was analysed simultaneously with the food samples using the same procedures.

The radioactivity of the solution pipetted into the upper chamber was not measured before incubation. Therefore, this initial radioactivity was calculated as the sum of the counts in the total content of the upper chamber, the counts in the total content of the lower chamber and the counts in the total volume of the cell monolayer.

Given the assumption of equilibration of the radioactive $\mathrm{Fe}$ and the food $\mathrm{Fe}$, the amount of $\mathrm{Fe}$ (radioactive + food $\mathrm{Fe}$ ) corresponding with 1 count per min (cpm) (nmol Fe/cpm) was calculated as the sum of the amount of radioactive $\mathrm{Fe}$ and the amount of food $\mathrm{Fe}$ in each sample before incubation (initial amount of $\mathrm{Fe}$ ) divided by the initial radioactivity.

The amount of $\mathrm{Fe}$ (food $\mathrm{Fe}+$ radioactive $\mathrm{Fe}$ ) that was left behind in the upper chamber (a), passed through the membrane (b), and was taken up by the cells after incubation (c), respectively, was calculated as follows:

(a) = counts in the total content of the upper chamber $\times$ nmol Fe/cpm;

(b) $=$ (counts in the total content of the lower chamber + counts in the total volume of the cell monolayer) $\times \mathrm{nmol} \mathrm{Fe} / \mathrm{cpm}$;

(c) $=$ counts in the total volume of the cell monolayer $\times \mathrm{nmol} \mathrm{Fe} / \mathrm{cpm}$.

The proportion of the $\mathrm{Fe}$ (food $\mathrm{Fe}+$ radioactive $\mathrm{Fe}$ ) initially in the food samples that was left behind in the upper chamber (d), passed through the membrane (e) and was taken up by the cells after incubation (f), respectively, was calculated as follows:

$$
\begin{aligned}
(\mathrm{d})= & \text { (amount of Fe left behind in the upper chamber } / \\
& \text { initial amount of } \mathrm{Fe}) \times 100
\end{aligned}
$$

(e) $=$ (amount of Fe passed the membrane/

initial amount of $\mathrm{Fe}) \times 100$;

(f) $=$ (amount of Fe taken up by the cells/

initial amount of $\mathrm{Fe}) \times 100$.

The amount of $\mathrm{Fe}$ (food $\mathrm{Fe}+$ radioactive $\mathrm{Fe}$ ) taken up by the cells as a proportion of the $\mathrm{Fe}$ that passed the membrane (g) was calculated as follows:

$$
(\mathrm{g})=(\text { amount of Fe taken up by the cells/amount of }
$$

Fe passed the membrane) $\times 100$.

The absolute amount of $\mathrm{Fe}$ (food $\mathrm{Fe}+$ radioactive $\mathrm{Fe}$ ) taken up by the cells per mg cell protein (thus adjusting for the number of Caco-2 cells in the well) was calculated as the amount of Fe taken up by the cells divided by the protein concentration in the cell monolayer.

\section{Analyses}

The quantity of ${ }^{55} \mathrm{Fe}$ was measured by counting in a Packard liquid scintillation analyser (Pangbourne, Berkshire, UK). Protein was determined using a Pierce BCA protein assay reagent kit (Rockford, IL, USA). Statistical analysis was carried out with the SPSS software (SPSS Inc., Chicago, IL, USA). Food samples were measured in triplicate for both the Caco2 cell culture method and the solubility method and means of the three measurements were used for the statistical analyses. A Kolmogorov-Smirnov test was used to test for normality. Both the percentage soluble $\mathrm{Fe}$ and Fe uptake by the Caco-2 cells were normally distributed in the processed and unprocessed samples, but because the number of samples was relatively small, a non-parametric test (Mann-Whitney U test) was used to compare the two groups of samples. A $P$ value of 0.05 was taken as the threshold for significance.

\section{Results}

Table 1 presents the $\mathrm{Fe}$ availability of the processed $v$. the unprocessed $\mathrm{CF}$ determined by the solubility method and the in vitro digestion-Caco- 2 cell culture method.

\section{Solubility method}

The mean percentage of soluble Fe was almost 19 in the processed samples, compared with approximately 5 in the unprocessed samples. This difference was statistically significant $(P<0 \cdot 001)$.

\section{In vitro digestion-Caco-2 cell culture method}

In the processed samples the mean percentage of the initial amount of $\mathrm{Fe}$ (food $\mathrm{Fe}+$ radioactive $\mathrm{Fe}$ ) that was left behind in the upper chamber was approximately 89 compared with 92 in the unprocessed samples $(P=0.028)$. Logically, a significant higher proportion of $\mathrm{Fe}$ had passed through the membrane in the processed samples. However, a mean percentage of $0 \cdot 3$ was taken up by the cells in the processed foods compared with 0.7 in the unprocessed samples. The latter was not significantly different $(P=0 \cdot 114)$.

The amount of $\mathrm{Fe}$ (food $\mathrm{Fe}+$ radioactive $\mathrm{Fe}$ ) taken up by the Caco-2 cells, as a proportion of the Fe that passed the membrane, was significantly higher in the unprocessed samples in comparison with the processed samples $(P=0 \cdot 007)$.

The absolute amount of $\mathrm{Fe}$ (food $\mathrm{Fe}+$ radioactive $\mathrm{Fe}$ ) that was taken up by the Caco- 2 cells per mg cell protein was highest for the unprocessed samples (mean 3.4 (SEM 0.83) nmol/mg 
Table 1. Iron availability of processed $v$. unprocessed complementary food (CF) determined by the solubility method and the in vitro digestion-Caco-2 cell culture method

(Mean values with their standard errors)

\begin{tabular}{|c|c|c|c|c|c|c|c|}
\hline & \multicolumn{2}{|c|}{$\begin{array}{l}\text { Control (no food sample) } \\
\qquad(n 4)\end{array}$} & \multicolumn{2}{|c|}{$\begin{array}{c}\text { Processed CF } \\
(n 12)\end{array}$} & \multicolumn{2}{|c|}{$\begin{array}{l}\text { Unprocessed CF } \\
(n 12)\end{array}$} & \multirow[b]{2}{*}{$P^{*}$} \\
\hline & Mean & SEM & Mean & SEM & Mean & SEM & \\
\hline \multicolumn{8}{|l|}{ Solubility method } \\
\hline \multicolumn{3}{|c|}{$\begin{array}{l}\text { Soluble } \mathrm{Fe}(\%) \\
\text { In vitro digestion-Caco- } 2 \text { cell culture method }\end{array}$} & $18 \cdot 8$ & 0.21 & $4 \cdot 8$ & 0.23 & $<0.001$ \\
\hline Fe left in upper chamber (\%)† & $80 \cdot 1$ & 1.77 & $88 \cdot 5$ & $1 \cdot 16$ & 91.5 & 2.54 & 0.028 \\
\hline Fe taken up by the cells (\%)†† & 0.8 & 0.18 & 0.3 & 0.04 & 0.7 & 0.19 & 0.114 \\
\hline Fe taken up by the cells $(\%) \dagger \S$ & $4 \cdot 1$ & 0.89 & $3 \cdot 0$ & 0.40 & $11 \cdot 7$ & $2 \cdot 22$ & 0.007 \\
\hline
\end{tabular}

${ }^{*} P$ value for the difference between processed and unprocessed CF.

$\dagger$ Food $\mathrm{Fe}+$ radioactive $\mathrm{Fe}$.

$\ddagger$ As a proportion of the amount of $\mathrm{Fe}$ in the samples.

$\S$ As a proportion of the amount of $\mathrm{Fe}$ that passed the membrane.

cell protein) compared with the processed samples (mean 1.3 (SEM $0 \cdot 16) \mathrm{nmol} / \mathrm{mg}$ cell protein). This difference was, however, not statistically significant $(P=0 \cdot 052)$ (see Fig. 1).

\section{Discussion}

Fe bioavailability is the proportion of total Fe in a food or diet that is digested, absorbed and utilised primarily for $\mathrm{Hb}$ synthesis (Fairweather-Tait, 1987). It can be predicted by studying the behaviour of $\mathrm{Fe}$ at different steps (digestion, absorption and utilisation), depending on the research question and technical, economic and ethical constraints. In the present paper two methods to assess Fe bioavailability were compared: a solubility method, which measures the solubilisation of $\mathrm{Fe}$ following simulated gastric and duodenal digestion; an in vitro Caco-2 cell uptake method, which simulates $\mathrm{Fe}$ uptake in the intestinal tract.

Fe needs to be in solution before it can be taken up by the enterocytes. In the diet non-haem Fe is mostly present in the

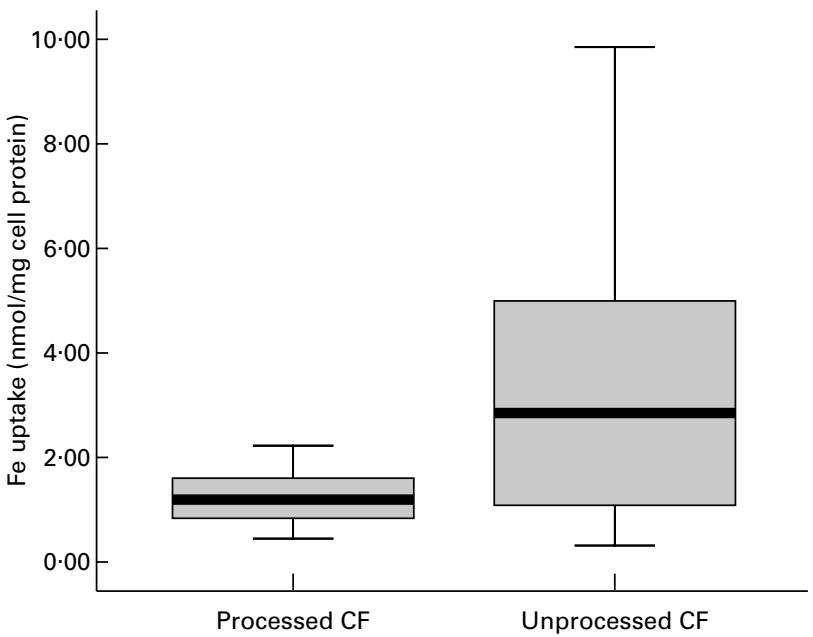

Fig. 1. Box and whisker plot of the distribution of the Fe uptake (food $\mathrm{Fe}+$ radioactive $\mathrm{Fe}$ ) ( $\mathrm{nmol} / \mathrm{mg}$ cell protein) by the Caco-2 cells of the processed and unprocessed complementary food (CF) samples. Each box represents the interquartile range, which contains $50 \%$ of values. The whiskers (I) extend from the boxes to the highest and lowest values. Medians are indicated by horizontal lines across the boxes. oxidised ferric form $\left(\mathrm{Fe}^{3+}\right)$, which is insoluble at intestinal $\mathrm{pH}$, unless it is bound in a chelate (Conrad \& Umbreit, 2002). The acid environment of the stomach removes Fe from food and helps to solubilise $\mathrm{Fe}$ by reducing ferric $\mathrm{Fe}$ to ferrous $\mathrm{Fe}\left(\mathrm{Fe}^{2+}\right)$, which is soluble at intestinal $\mathrm{pH}$. Ferrous $\mathrm{Fe}$ has a high tendency to become oxidised to the ferric form and therefore a reducing or chelating environment is needed in order to keep the Fe soluble (Beard et al. 1996; Conrad \& Umbreit, 2002). In view of this, an assessment of soluble (reduced) Fe in the digest ('solubility method') is likely to represent a useful measure of the proportion of Fe that is effectively available for absorption, after the usual digestion processes in the human gastrointestinal tract. It is also generally assumed that this measurement correlates well with the fraction that is absorbed by the enterocyte. This method is moreover easy and rapid to perform and has a low cost. It is therefore not surprising that this method is widely used to evaluate the effect of different processing techniques on the solubility of $\mathrm{Fe}$ and other minerals (Duhan et al. 1999, 2002; Valencia et al. 1999; Mamiro et al. 2001; Yadav \& Sehgal, 2002).

In a previous study, the solubility method was used to measure the effect of processing on the Fe bioavailability in $\mathrm{CF}$, especially developed for use in Tanzanian infants aged 6-12 months during their weaning period. The results of the solubility test predicted a much higher bioavailability in the processed matrix as compared with the unprocessed food. This contrasted sharply with the results of the field trial, in which no improvement in Fe status could be demonstrated in children who were fed with the processed food (Mamiro et al. 2004). An in-depth elaboration of the different elements that need to be taken into account in the interpretation of the discrepancy between expected and observed results in this experiment in Tanzanian infants can be found in the original publication (Mamiro et al. 2004). However, an overall conclusion from that field trial was that in vitro measurements of soluble $\mathrm{Fe}$ in a food matrix may be a poor predictor of changes in Fe status in populations with a high prevalence of Fe deficiency. This observation has led the authors to question the usefulness of the Fe solubility method for predicting absorption in the gastrointestinal tract.

It is known that $\mathrm{Fe}$ absorption is a complex process and the mechanisms by which this process is regulated remain 
incompletely understood. It could be hypothesised, however, that in the overall context of the complexity of Fe absorption, the solubility test is potentially a poor predictor of the actual absorption.

Since the body cannot actively excrete Fe, body Fe content must be regulated at the point of absorption. Increased rates of erythropoiesis and low ferritin levels are important stimuli for $\mathrm{Fe}$ absorption with increased expression of receptor sites for Fe on the enterocyte. However, Hahn et al. (1943) and later Stewart et al. (1950) demonstrated that large doses of $\mathrm{Fe}$ can actually reduce the absorption of a smaller dose of $\mathrm{Fe}$ that is consumed later. This so-called 'mucosal block theory' has also been used to explain poor responses in $\mathrm{Fe}$ status in a trial in which $\mathrm{Fe}$ was given daily or once or twice per week. Frazer et al. (2003) demonstrated that this phenomenon is accompanied by changes in the expression of brush-border Fe transport proteins, which are regulated to some extent by enterocyte Fe levels.

Caco- 2 cells have been shown to be a useful screening tool for estimating bioavailability and are increasingly used to study molecular mechanisms of Fe transport and uptake. Significant correlations between Fe uptake by Caco- 2 cells from semi-synthetic meals and human absorption data have well been described (Au \& Reddy, 2000; Yun et al. 2004). In vitro digestion-Caco-2 cell culture models confirmed the inhibitory effect of phytic acid, tannic acid and $\mathrm{Zn}$ on $\mathrm{Fe}$ uptake successfully (Glahn et al. 2002b). Thus the Caco-2 cells have demonstrated their capacity to estimate bioavailability.

In contrast to predictions made from Fe solubility data, the results of the Tanzanian intervention study are in accord with the data generated from the Caco- 2 cell model for Fe bioavailability described in the present paper. In the intervention study no significant differences were found for growth and $\mathrm{Fe}$ status parameters between the intervention group and control group. This in vivo observation fits well with the absence of a statistically significant difference for $\mathrm{Fe}$ uptake by $\mathrm{Caco}-2$ cells between the processed and unprocessed CF samples, but contrasts sharply with the results of the solubility method that predicted a higher bioavailability in the processed samples. In the Caco-2 model, the results of the percentage Fe left behind in the upper chamber and passed through the membrane are as predicted from the results of the solubility test, since the greater the quantity of soluble Fe there is in the sample, the more $\mathrm{Fe}$ can be expected to pass through the membrane and the less will be left behind in the upper chamber. Apart from the unstirred layer, no such membranes are present in the human digestive tract. However, the mucus layer of the lumen has been shown to be permeable to ions and smaller molecules and impermeable to large proteins, and so protects the gastroduodenal mucosa from autodigestion (Allen \& Carroll, 1985; Allen et al. 1993). In vitro, the membranes protect the Caco- 2 cell monolayer from the enzymes used for the simulation of the digestive process. In contrast, the similarity of the results of the solubility test and the percentage Fe passing through the membrane conflicts with the observed $\mathrm{Fe}$ uptake by the Caco- 2 cells. Since Fe solubility in the processed samples was significantly higher than in the unprocessed samples, significantly more soluble $\mathrm{Fe}$ is being presented to the Caco- 2 cells in the processed samples. However, proportionally less Fe has been taken up by the Caco-2 cells in the processed samples compared with the unprocessed samples. The net result is that no significant difference is observed between processed and unprocessed samples for absolute Fe uptake in the Caco- 2 cells. The reason for this differential result in proportional $\mathrm{Fe}$ uptake remains unclear. It may be possible that these changes relate to an alteration in the content and/or activity of specific compounds in the flours as a result of processing (Watzke, 1998). There is also the inhibitory effect of the polyphenolic polymers (tannins) in the food samples, which were decreased to undetectable levels in the processed samples (Mbithi-Mwikya et al. 2002). It could, however, be that the inhibitory effect of tannins was maintained after processing (Glahn et al. 2002a). Processing would break down polymers and the resulting monomer compounds may bind $\mathrm{Fe}$, thereby inhibiting $\mathrm{Fe}$ absorption. Since phytate levels were reduced by processing but no significant increase was seen in Fe availability, polyphenolic compounds may be the primary inhibitory component, but further studies are required to confirm this.

There may be problems with the isotopic exchange in the extrinsic labelling technique used to measure Caco-2 cell $\mathrm{Fe}$ uptake, particularly with high levels of phytate and polyphenolics in the samples. Thus, caution needs to be taken when interpreting the results. The alternative method patented by Glahn et al. (1998) in which ferritin is used as a surrogate marker of $\mathrm{Fe}$ uptake over a more prolonged time-scale has different potential problems. Ferritin may be expressed in conditions of oxidative stress and inflammation, and not just a quantitative response to $\mathrm{Fe}$ (Fairweather-Tait et al. 2006). Nevertheless, the results of the present study clearly indicate that the solubility method can be misleading as far as absorption in the gastrointestinal tract is concerned, whereas the Caco- 2 cell method concurs with in vivo data. This overall conclusion has important consequences for the assessment and evaluation of food-based interventions aimed at $\mathrm{Fe}$ deficiency and for clinical and epidemiological research that is carried out in this field.

\section{Acknowledgements}

The authors thank Dr Liz Lund from the Institute of Food Research (Norwich, UK) for her advice by performing the experiment. The present study was financially supported by the European Commission, Marie Curie Host Fellowship and Nutrition Tiers Monde.

\section{References}

Allen A \& Carroll N (1985) Adeherent and soluble mucus in the stomach and duodenum. Dig Dis Sci 30, Suppl. 11, 55S-62S.

Allen A, Flemstrom G, Garner A \& Kivilaakso E (1993) Gastroduodenal mucosal protection. Physiol Rev 73, 823-857.

Association of Official Analytical Chemists (1995) Official Methods of Analysis, 16th ed. Arlington, VA: AOAC International.

Au A \& Reddy M (2000) Caco-2 cells can be used to assess human iron bioavailability from a semipurified meal. J Nutr 130, 1329-1334.

Beard J, Dawson H \& Pinero D (1996) Iron metabolism: a comprehensive review. Nutr Rev 54, 295-317.

Conrad M \& Umbreit J (2002) Pathways of iron absorption. Blood Cells Mol Dis 29, 336-355. 
Duhan A, Khetarpaul N \& Bishnoi S (1999) Effect of various domestic processing and cooking methods on phytic acid and $\mathrm{HCl}$ extractability of calcium, phosphorus and iron of pigeon pea. Nutr Health 13, 161-169.

Duhan A, Khetarpaul N \& Bishnoi S (2002) Changes in phytates and $\mathrm{HCl}$ extractability of calcium, phosphorus, and iron of soaked, dehulled, cooked, and sprouted pigeon pea cultivar (UPAS-120). Plant Foods Hum Nutr 57, 275-284.

Fairweather-Tait S (1987) The concept of bioavailability as it relates to iron nutrition. Nutr Res 7, 319-325.

Fairweather-Tait S, Lynch S, Hotz C, et al. (2006) The usefulness of in vitro models to predict the bioavailability of iron and zinc: a consensus statement from the HarvestPlus Consultation. Int $J$ Vitam Nutr Res, (In the Press).

Frazer D, Wilkins S, Becker E, Murphy T, Vulpe C, McKie A \& Anderson G (2003) A rapid decrease in the expression of DMT1 and Dcytb but not Ireg1 or hephaestin explains the mucosal block phenomenon of iron absorption. Gut 52, 340-346.

Glahn R, Cheng Z \& Welch R (2002a) Comparison of iron bioavailability from 15 rice genotypes: studies using an in vitro digestion/ Caco-2 cell culture model. J Agric Food Chem 50, 3586-3591.

Glahn R, Lee O, Yeung A, Goldman M \& Miller D (1998) Caco-2 cell ferritin formation predicts nonradiolabeled food iron availability in an in vitro digestion/Caco-2 cell culture model. J Nutr 128, 1555-1561.

Glahn R, Wien E, van Campen D \& Miller D (1996) Caco-2 cell iron uptake from meat and casein digests parallels in vivo studies: use of a novel in vitro method for rapid estimation of iron bioavailability. J Nutr 126, 332-339.

Glahn R, Wortley G, South P \& Miller D (2002b) Inhibition of iron uptake by phytic acid, tannic acid, and $\mathrm{ZnCl}_{2}$ : studies using an in vitro digestion/Caco-2 cell model. J Agric Food Chem 50, 390-395.

Hahn P, Bale W, Ross J, Balfour W \& Whipple G (1943) Radioactive iron absorption by gastro-intestinal tract: influence of anemia, anoxia, and antecedent feeding distribution in growing dogs. $J$ Exp Med 78, 169-188.

Kimanya M, Mamiro P, Van Camp J, Devlieghere F, Opsomer A, Kolsteren P \& Debevere J (2003) Growth of Staphylococcus aureus and Bacillus cereus during germination and drying of finger millet and kidney beans. Int J Food Sci Technol 38, 119-125.

Kramer M \& Kakuma R (2002) Optimal duration of exclusive breastfeeding. Cochrane Database Syst Rev 1, CD003517.

Mamiro P, Kolsteren P, van Camp J, Roberfroid D, Tatala S \& Opsomer A (2004) Processed complementary food does not improve growth or hemoglobin status of rural Tanzanian infants from 6-12 months of age in Kilosa district. Tanzania. J Nutr 134, 1084-1090.

Mamiro P, van Camp J, Mwikya S \& Huyghebaert A (2001) In vitro extractability of calcium, iron and zinc in finger millet and kidney beans during processing. J Food Sci 66, 1271-1275.

Mbithi-Mwikya S, Van Camp J, Mamiro P, Ooghe W, Kolsteren P \& Huyghebaert A (2002) Evaluation of the nutritional characteristics of a finger millet based complementary food. J Agric Food Chem 50, 3030-3036.

Mensah P \& Tomkins A (2003) Household-level technologies to improve the availability and preparation of adequate and safe complementary foods. Food Nutr Bull 24, 104-125.

Michaelsen K \& Friis H (1998) Complementary feeding: a global perspective. Nutrition 14, 763-766.

Miller D, Schricker B, Rasmussen R \& van Campen D (1981) An in vitro method for estimation of iron availability from meals. Am J Clin Nutr 34, 2248-2256.

Stewart W, Yuile C, Claiborne H, Snowman R \& Whipple G (1950) Radioiron absorption in anemic dogs; fluctuations in the mucosal block and evidence for a gradient of absorption in the gastrointestinal tract. J Exp Med 92, 375-382.

United Nations International Children's Emergency Fund (2003). The state of the world's children 2003, accessed 5/1/2006. http://www. unicef.org/sowc03/index.html

United Nations Standing Committee on Nutrition (2004) 5th Report on the World Nutrition Situation. Nutrition for Improved Development Outcomes. Geneva: WHO.

Valencia S, Svanberg U, Sandberg A \& Ruales J (1999) Processing of quinoa (Chenopodium quinoa, Willd): effects on in vitro iron availability and phytate hydrolysis. Int J Food Sci Nutr 50, 203-211.

Watzke H (1998) Impact of processing on bioavailability examples of minerals in foods. Trends Food Sci Technol 9, 320-327.

World Health Organization (2001) Iron Deficiency Anaemia: Assessment, Prevention and Control. A Guide for Programme Managers. Document WHO/NHD/01.3. Geneva: WHO.

Yadav S \& Sehgal S (2002) Effect of domestic processing and cooking methods on total, $\mathrm{HCl}$ extractable iron and in vitro availability of iron in spinach and amaranth leaves. Nutr Health 16, 113-120.

Yun S, Habicht J-P, Miller D \& Glahn R (2004) An in vitro digestion/ Caco-2 cell culture system accurately predicts the effects of ascorbic acid and polyphenolic compounds on iron bioavailability in humans. J Nutr 134, 2717-2721. 